\title{
Gaya Kepemimpinan dan Komitmen Paramedis dalam Implementasi Akreditasi Rumah Sakit Versi SNARS
}

\author{
Daniel Ginting ${ }^{1 *}$, Nina Fentiana ${ }^{2}$, Tiara Rajagukguk ${ }^{3}$, Harry Wahyudi ${ }^{4}$ \\ 1,4 Direktorat Pascasarjana USM-Indonesia, \\ Gedung Pascasarjana Lantai 1 Jalan Kapten Muslim No 79 Medan 20128, Indonesia \\ 2 Kesehatan Masyarakat Fakultas Farmasi dan IImu Kesehatan, USM-Indonesia, \\ Lantai 2 Gedung Baru Jalan Kapten Muslim No 79 Medan 20128, Indonesia \\ ${ }^{3}$ Analis Kesehatan Fakultas Farmasi dan IImu Kesehatan, USM-Indonesia, \\ Lantai 1 Gedung Mawar, Jalan Kapten Muslim No 79 Medan 20128, Indonesia \\ Correspondence email: fentiana.nina@gmail.com
}

\begin{abstract}
Abstrak. Pasal 40 ayat (1) UU Nomor 44 tahun 2009 tentang Rumah Sakit disebutkan bahwa dalam upaya meningkatkan mutu pelayanan rumah sakit wajib dilakukan akreditasi secara berkala minimal tiga tahun sekali. Rancangan kepemimpinan diperlukan untuk mendukung terbentuknya komitmen paramedis dalam implementasi akreditasi. Penelitian bertujuan mengidentifikasi gaya kepemimpinan para pimpinan langsung paramedis dan komitmen paramedis dalam implementasi akreditasi versi SNARS. Penelitian dirancang dengan pendekatan cross sectional di RS Delia dengan jumlah sampel 79 orang tenaga paramedis dan menggunakan data primer yang diperoleh melalui observasi dan wawancara. Uji korelasi dan regresi linier sederhana memperlihatkan gaya kepemimpinan dan komitmen paramedis dalam implementasi akreditasi rumah sakit menunjukkan hubungan yang kuat dan berpola positif. Hasil penelitian menyimpulkan bahwa gaya kepemimpinan orientasi prestasi adalah gaya kepemimpinan yang dianggap paling mampu membangun komitmen paramedis dalam implementasi akreditasi.
\end{abstract}

Kata kunci : Akreditasi; Kepemimpinan; Paramedis; Rumah Sakit.

Abstract. Clause 40 paragraph (1) of Law Number 44 of 2009 concerning Hospitals states that in an effort to improve the quality of hospital services, accreditation must be carried out periodically at least every three years. The leadership design is needed to support the formation of paramedic commitments in the implementation of accreditation. The research aims to identify the leadership style of direct paramedic leaders and paramedic commitment in the implementation of SNARS version accreditation. The study was designed with a cross sectional approach at Delia Hospital with a sample of 79 paramedics and using primary data obtained through observation and interviews. Correlation and simple linear regression tests showed leadership style and paramedic commitment in implementing hospital accreditation showed a strong and positive pattern of relationships. The results of the study concluded that achievement-oriented leadership style is the leadership style that is considered the most able to build paramedic commitment in the implementation of accreditation.

Keywords : Accreditation; Leadership; Paramedic; Hospital.

\section{PENDAHULUAN}

Undang-Undang Nomor 44 Tahun 2009 Tentang Rumah Sakit, Pasal 29 huruf b menjelaskan bahwa rumah sakit wajib memberikan pelayanan kesehatan yang aman, bermutu, anti diskriminasi dan efektif dengan mengutamakan kepentingan pasien sesuai dengan standar pelayanan rumah sakit. Pasal 40 ayat (1) UU nomor 44 tahun 2009 juga menyebut bahwa dalam upaya meningkatkan mutu pelayanan rumah sakit wajib dilakukan akreditasi secara berkala minimal tiga tahun sekali. (Kemenkes, 2009) Dari undang undang tersebut diatas akreditasi rumah sakit penting untuk dilakukan dengan alasan agar mutu dan kualitas diintegrasikan dan dibudayakan ke dalam sistem pelayanan di rumah sakit ditambah lagi BPJS mensyaratkan bekerjasama dengan rumah sakit yang sudah terakreditasi.

Permenkes No 12 Tahun 2012 Tentang Akreditasi Rumah Sakit menyebutkan bahwa akreditasi adalah pengakuan terhadap Rumah Sakit yang diberikan oleh lembaga independen penyelenggara akreditasi yang ditetapkan oleh Menteri, setelah dinilai bahwa rumah sakit itu memenuhi standar pelayanan rumah sakit yang berlaku untuk meningkatkan mutu pelayanan rumah sakit secara berkesinambungan. (Kemenkes, 2012) Permenkes 56 pasal 76 ayat (2) tahun 2014 tentang klasifikasi dan perijanan rumah sakit menyatakan bahwa akreditasi merupakan persyaratan untuk perpanjangan izin dan perubahan kelas rumah sakit. (Kemenkes, 2014) Proses akreditasi rumah sakit penting karena akreditasi mampu meningkatkan kepercayaan masyarakat terutama yang berhubungan dengan keselamatan pasien dan peningkatan mutu pelayanan di rumah sakit.

Sumber daya manusia (SDM) memegang peranan yang sangat dominan dalam aktivitas atau kegiatan rumah sakit, terutama paramedis. Berhasil atau tidaknya sebuah rumah sakit dalam mencapai tujuan akreditasi sangat tergantung pada kemampuan sumber daya manusianya (paramedis dan tenaga lain nya) dalam menjalankan tugas-tugas yang diberikan. Oleh karena itu, setiap manajemen rumah sakit perlu memikirkan bagaimana cara yang dapat dilakukan untuk mengembangkan kemampuan paramedis dan pegawai lainnya agar dapat mendorong kemajuan untuk tercapai tujuan akreditasi rumah sakit. (Aditama, 2013)

Dalam setiap organisasi, paramedis/pegawai lainnya bekerja selalu tergantung pada pimpinan. Bila pimpinan tidak memiliki kemampuan memimpin, maka tugas-tugas yang sangat kompleks tidak dapat dikerjakan dengan baik. Apabila pimpinan mampu melaksanakan fungsi-fungsinya dengan baik, sangat memungkin rumah sakit tersebut dapat mencapai tujuannya. Suatu rumah sakit membutuhkan pemimpin 
yang efektif, yang mempunyai kemampuan mempengaruhi perilaku anggotanya atau anak buahnya.

(Restiawati, 2013)

Data bagian SDM Rumah sakit Delia melaporkan jumlah tenaga paramedis tahun 2016 tercatat sebanyak 92 orang (69 orang bidan dan 23 orang perawat) dan tahun 2017 terdapat 105 tenaga paramedis yang terdiri dari 78 orang bidan dan 27 orang perawat. Tingginya jumlah tenaga paramedis ini tidak diikuti dengan tingginya komitmen paramedis dalam bekerja yang salah satunya ditunjukkan dari laporan paramedis resign. Bagian SDM juga melaporkan bahwa tahun 2016 sebanyak 6 orang paramedis resign dan 11 orang paramedis resign ditahun 2017. Rendahnya komitmen paramedis dalam bekerja juga ditunjukkan dari banyaknya paramedis yang menolak mengerjakan pekerjaan diluar tugas pokok, ini dibuktikan dari rendahnya paramedis yang berpartisipasi dalam rapat akreditasi (hanya $20-30 \%$ paramedis yang hadir). Tim akreditasi Rumah Sakit Delia terbentuk namun paramedis banyak yang menolak terlibat menjadi anggota tim akreditasi. Mengacu pada kondisi diatas maka dirancang penelitian guna mengidentifikasi gaya kepemimpinan para pimpinan langsung paramedis dan komitmen paramedis dalam implementasi akreditasi versi SNARS.

\section{METODE PENELITIAN}

Rancangan penelitian menggunakan pendekatan cross sectional yang dilakukan di RS Delia dengan jumlah keseluruhan paramedis adalah 98 orang. Besaran sampel dihitung menggunakan rumus Slovin dan jumlah sampel yang diperoleh adalah 79 orang terdiri dari 59 orang bidan dan 20 orang perawat. Data yang digunakan adalah data primer yang diperoleh melalui observasi dan wawancara. Analisis data dilakukan bertahap meliputi analisis univariat, bivariat dan multivariat. Analaisis univariat untuk mendeskripsikan karakteristik paramedis dalam implementasi akreditasi rumah sakit. Analisis bivariat menggunakan uji korelasi dan regresi linier sederhana dan analisis multivariat menggunakan regresi linier ganda.

\section{HASIL DAN PEMBAHASAN Karakeristik Responden}

Karakteristik responden berdasarkan jenis kelamin didominasi oleh wanita $(86,1 \%)$ dengan tingkat pendidikan D3 (86,1\%). Berdasarkan usia responden hampir merata berusia $20-30$ tahun (82,3\%) dan memiliki masa kerja pada umumnya kurang dari 5 tahun $(87,3 \%)$. Secara lengkap karakteristik responden disajikan pada tabel 1.

Tabel 1. Distribusi Responden Berdasarkan Jenis Kelamin, Pendidikan, Usia

\begin{tabular}{lccc}
\hline \multicolumn{2}{c}{ Jenis Kelamin } & f & $\%$ \\
\hline Pria & 11 & 13,9 \\
Wanita & 68 & 86,1 \\
\hline \multicolumn{2}{c}{ Pendidikan } & $\mathbf{f}$ & $\%$ \\
\hline D3 & 68 & 86,1 \\
S1/Profesi & 11 & 13,9 \\
\hline \multicolumn{2}{c}{ Usia (tahun) } & $\mathbf{f}$ & $\%$ \\
\hline$<20$ & 5 & 6,3
\end{tabular}

\begin{tabular}{lcc}
$\begin{array}{l}20-30 \\
\geq 30\end{array}$ & 65 & 82,3 \\
\hline Masa Kerja (tahun) & 9 & 11,4 \\
\hline$<5$ & $\mathbf{f}$ & $\%$ \\
$\geq 5$ & 69 & 87,3 \\
\hline
\end{tabular}

\section{Gaya kepemimpinan dan komitmen paramedis}

Hasil uji korelasi gaya kepemimpinan diperoleh nilai korelasi ( $r$ ) 0,493-0,686 yang menunjukkan gaya kepemimpinan dan komitmen paramedis memiliki hubungan yang kuat dan berpola positif artinya semakin baik gaya kepemimpinan maka semakin baik komitmen paramedis yang terbentuk. Nilai p-value 0,0005 artinya ada hubungan yang signifikans antara gaya kepemimpinan dan komitmen paramedis, secara lengkap nilai korelasi ( $r$ ) dan nilai $p$-value disajikan pada tabel 2 .

Tabel 2. Pengaruh Gaya Kepemimpinan Terhadap Komitmen Paramedis

\begin{tabular}{rlccr}
\hline No & \multicolumn{1}{c}{ Variabel } & $\mathrm{r}$ & $\mathrm{R}^{2}$ & $\mathrm{p}$-Value \\
\hline & $\begin{array}{l}\text { Gaya kepemimpinan } \\
\text { pengarah }\end{array}$ & 0,677 & 0,459 & 0,0005 \\
& $\begin{array}{l}\text { Gaya kepemimpinan } \\
\text { pendukung }\end{array}$ & 0,493 & 0,243 & 0,0005 \\
& $\begin{array}{l}\text { Gaya kepemimpinan } \\
\text { peran serta }\end{array}$ & 0,529 & 0,280 & 0,0005 \\
4 & $\begin{array}{l}\text { Gaya kepemimpinan } \\
\text { berorientasi prestasi }\end{array}$ & 0,659 & 0,435 & 0,0005 \\
5 & $\begin{array}{l}\text { Gaya kepemimpinan } \\
\text { pengasuh }\end{array}$ & 0,686 & 0,471 & 0,0005 \\
\hline
\end{tabular}

Uji regresi linier sederhana menunjukkan nilai koefesien determinasi $\left(R^{2}\right) \quad 0,243-0,471$ artinya persamaan garis regresi yang diperoleh dapat menerangkan $24,3 \%-47,1 \%$ variasi komitmen paramedis atau persamaan garis yang diperoleh cukup baik untuk menjelaskan variabel komitmen paramedis. Persamaan garis regresi linier sederhana dan komitmen paramedis secara lengkap disajikan sebagai berikut.

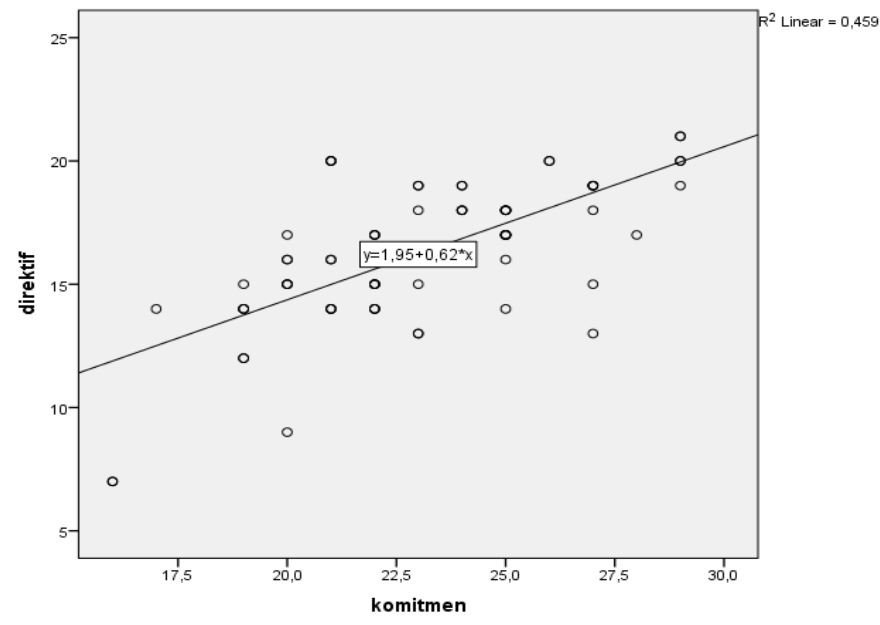

Gambar 1. Garis Regresi Gaya Kepemimpinan Pendukung 


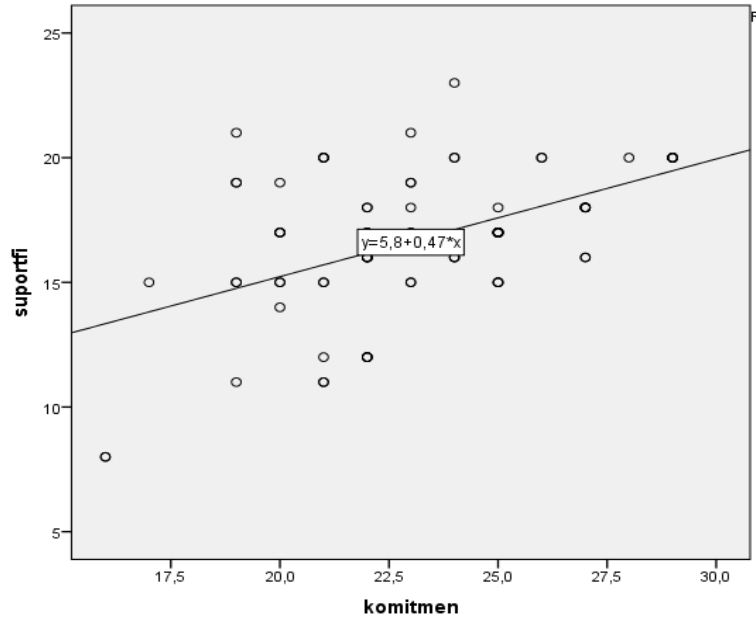

Gambar 2. Garis Regresi Gaya Pengarah

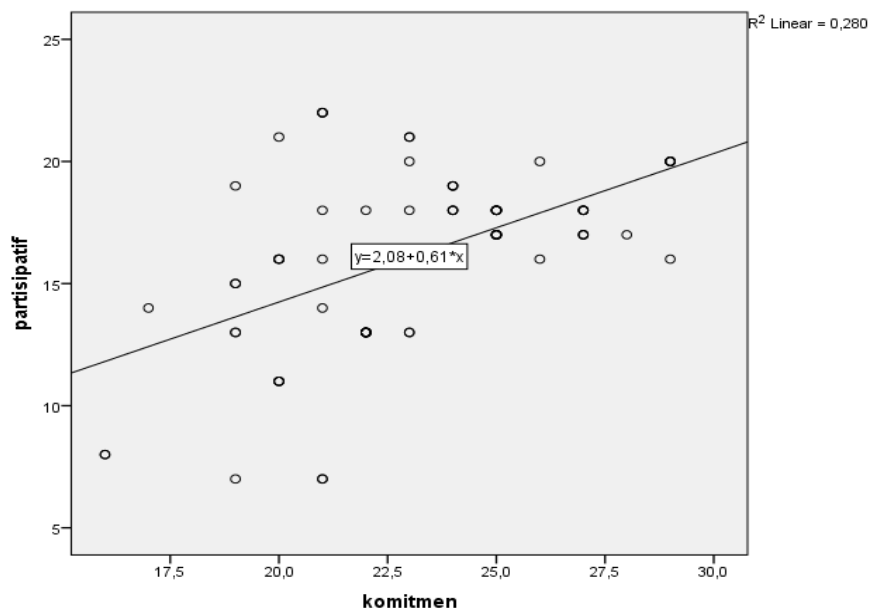

Gambar 3. Garis Regresi Gaya Kepemimpinan Peran Serta

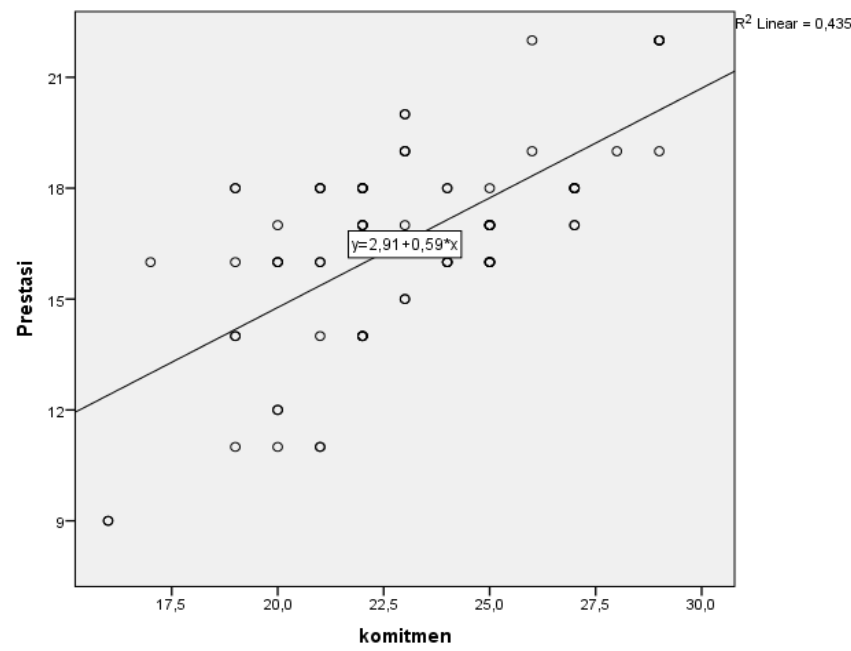

Gambar 4. Garis Regresi Gaya Orientasi Prestasi

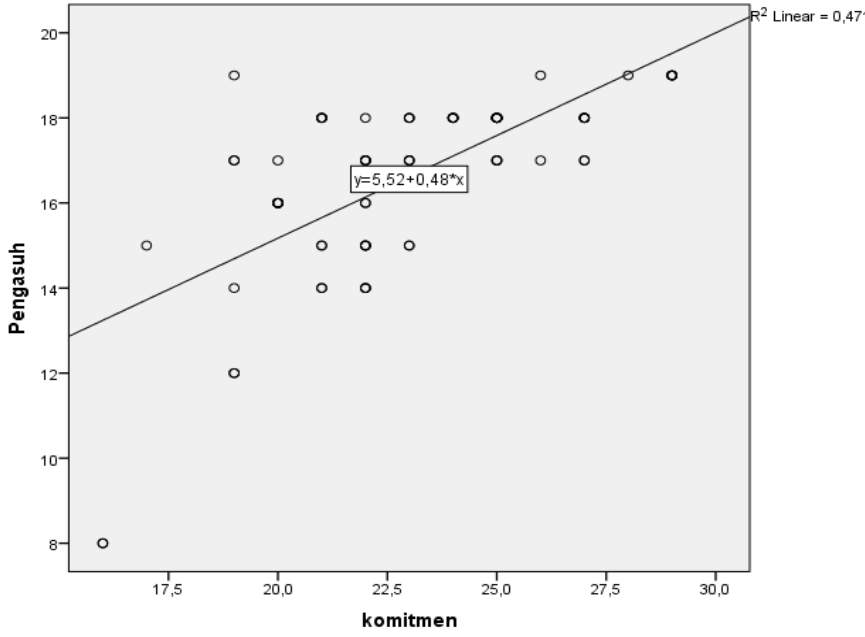

Gambar 5. Garis Regresi Gaya Kepemimpinan Pengasuh

Analisis multivariat dilakukan menggunakan analisis regresi linier ganda karena variabel dependent dan independent disajikan dalam bentuk numerik. Tahapan analisis multivariat yang dilakukan adalah pemilihan kandidat multivariat dan pembuatan model. Setelah dilakukan analisis, ternyata variabel independen yang masuk model regresi adalah gaya kepemimpinan pengarah, gaya kepemimpinan pendukung, gaya kepemimpinan berorientasi prestasi dan gaya kepemimpinan pengasuh. Variabel gaya kepemimpinan peran serta dikeluarkan dari model regresi karena pada langkah awal pemilihan kandidat model (seleksi bivariat) varibel gaya kepemimpinan peran serta memiliki $p$-value $>0,25$ (yaitu $p$-value $=0,851$ ) sehingga tidak bisa masuk ke model multivariat. Pemodelan multivariat ini sudah memenuhi syarat uji Aumsi yaitu asumsi eksistensi (berkaitan dengan teknik pengambilan sampel), asumsi independensi (bahwa nilai yang diukur tiap individu saling berdiri sendiri), asumsi linieritas (model membentuk persamaan regresi), asumsi homoscedascity (data bervarian), dan asumsi normalitas (data terdistribusi normal). Kolom beta digunakan untuk mengetahui variabel mana yang paling besar pengaruhnya terhadap variabel dependen (komitmen paramedis dalam implementasi akreditasi rumah sakit). Hasil uji memperlihatkan variabel yang paling besar pengaruhnya terhadap komitmen paramedis dalam implementasi akreditasi rumah sakit adalah gaya kepemimpinan berorientasi prestasi.

Tabel 3. Analisa Regresi Linier Ganda Gaya Kepemimpinan dan Komitmen Paramedis

\begin{tabular}{cccccc}
\hline No & \multicolumn{1}{c}{ Variabel } & B & Std.Eror & Beta & Sig \\
\hline & $\begin{array}{l}\text { Gaya } \\
\text { kepemimpinan } \\
\text { pengarah } \\
\text { Gaya }\end{array}$ & 0,279 & 0,122 & 0,255 & 0,025 \\
& $\begin{array}{l}\text { kepemimpinan } \\
\text { pendukung } \\
\text { Gaya } \\
\text { kepemimpinan } \\
\text { berorientasi prestasi } \\
\text { Gaya }\end{array}$ & 0,496 & 0,154 & 0,475 & 0,002 \\
& $\begin{array}{l}\text { kepemimpinan } \\
\text { pengasuh } \\
\text { Constant }\end{array}$ & 0,650 & 0,202 & 0,457 & 0,002 \\
5 & 5,707 & 1,731 & 0,557 & 0,001 \\
& & & 0,002 \\
\hline
\end{tabular}


Komitmen paramedis dalam implementasi akreditasi rumah sakit dipengaruhi oleh faktor individu yang terdiri dari kepribadian, usia, masa kerja, tingkat pendidikan dan jenis kelamin. Kepribadian merupakan faktor utama yang mempengaruhi perilaku dan komitmen individu dalam bekerja sedangkan usia, masa kerja, tingkat pendidikan dan jenis kelamin mempunyai efek tidak langsung pada komitmen paramedis. (Mamduh, 2010) Tabel karakteristik paramedis menunjukkan pada umumnya paramedis masih berlatar belakang pendidikan D3 dan masa kerja masih kurang dari 5 tahun. Hal ini menggambarkan paramedis masih minim pengalaman dalam melaksanakan tugasnya dan belum mempunyai rasa menjadi bagian dari keluarga besar rumah sakit sehingga dibutuhkan gaya kepemimpinan yang kuat untuk membangun komitmen paramedis dalam bekerja seperti yang diungkapkan Soekidjan tahun 2009 bahwa faktor organisasi berefek tidak langsung terhadap perilaku dan komitmen individu terdiri dari struktur organisasi, desain pekerjaan, kepemimpinan, sistem penghargaan. (Soekidjan, 2009)

Gaya Kepemimpinan merupakan suatu cara yang dimiliki oleh seseorang dalam mempengaruhi sekelompok orang atau bawahan untuk bekerja sama dan berdaya upaya dengan penuh semangat dan keyakinan untuk mencapai tujuan yang telah ditetapkan. Keberhasilan suatu organisasi baik sebagai keseluruhan maupun berbagai kelompok dalam suatu organisasi tertentu, sangat tergantung pada efektivitas kepemimpinan yang terdapat dalam organisasi yang bersangkutan. Dapat dikatakan bahwa mutu kepemimpinan yang terdapat dalam suatu organisasi memainkan peranan yang sangat dominan dalam keberhasilan organisasi tersebut dalam menyelenggarakan berbagai kegiatannya. ${ }^{8} \mathrm{Hasil}$ analisa regresi linier ganda menunjukkan variabel yang paling besar pengaruhnya terhadap komitmen paramedis dalam implementasi akreditasi rumah sakit adalah gaya kepemimpinan berorientasi prestasi. Hasil penelitian ini sejalan dengan penelitian Yulistian tahun 2011 bahwa secara parsial gaya kepemimpinan orientasi prestasi memiliki pengaruh signifikan terhadap semangat kerja karyawan, gaya kepemipinan orientasi prestasi yang berada pada tingkat kuat, didapatkan semangat kerja karyawan yang kuat pula. Hal ini karena karyawan merasa pemimpin dapat merangsang kinerja karyawan dan mengajukan tantangan pada karyawan. Sehingga karyawan percaya bahwa pemimpin dapat menjalankan tugasnya dengan baik, hal ini akan menimbulkan semangat kerja yang tinggi pada karyawan, apabila semangat kerja tinggi maka produktifitas kerja karyawan juga akan tinggi dan pada akhirnya tujuan perusahaan yang telah direncanakan dapat tercapai dengan baik. (Yulistian, 2011)

Hasil penelitian juga didukung oleh penelitian Widiyanti tahun 2012 tentang pengaruh gaya kepemimpinan berorientasi prestasi terhadap kinerja dengan variabel moderasi partisipasi pengambilan keputusan dan need for achievment yang menunjukkan bahwa ada pengaruh gaya kepemimpinan orientasi prestasi terhadap semangat karyawan dalam bekerja yang pada akhirnya memengaruhi kinerja. (Widiyanti, 2012)
Gaya kepemimpinan dimana pemimpin menetapkan tujuan yang menantang dan mengharapkan bawahan untuk berprestasi semaksimal mungkin serta terus menerus mencari pengembangan prestasi dalam pencapaian tujuan tersebut adalah kepemimpinan yang berorientasi prestasi. Tingkah laku individu didorong oleh need for achievement atau kebutuhan untuk berprestasi. Kepemimpinan yang berorientasi kepada prestasi (achievement) dihipotesakan akan meningkatkan usaha dan kepuasan bila pekerjaan tersebut tidak tersetruktur (misalnya kompleks dan tidak diulang-ulang) dengan meningkatkan rasa percaya diri dan harapan akan menyelesaikan sebuah tugas dan tujuan yang menantang. Kepuasan kerja lebih tinggi diperoleh apabila telah melaksanakan prestasi kerja yang baik. Pegawai yang memiliki kebutuhan untuk berkembang dan mengerjakan tugas-tugas sulit berdasarkan pembahasan konseptual sikap pemimpin yang paling tepat untuk pegawai ini adalah gaya partisipatif dan berorientasi prestasi. (Thoha, 2010)

Gaya kepemimpinan orientasi prestasi dalam penelitian ini mampu meningkatkan komitmen paramedis dalam implementasi akreditasi rumah sakit. Hal ini karena paramedis merasa bahwa apa yang dikerjakan berharga, paramedis merasa nyaman bekerja, paramedis merasa mendapat dukungan penuh dari pimpiman dan manajemen berupa misi dan nilainilai yang jelas yang berlaku di rumah Sakit. Rasa bergairah terhadap pekerjaan paramedis di rumah sakit timbul karena pimpinan memberi perhatian pada hasil kerja paramedis, pimpinan memberi delegasi wewenang kepada paramedis dalam implementasi akreditasi, serta memberi kesempatan serta ruang yang cukup bagi paramedis untuk menggunakan keterampilan dan keahliannya secara maksimal. Pimpinan rumah sakit juga melibatkan paramedis dalam membuat keputusankeputusan yang berhubungan dengan implementasi akreditasi rumah sakit.

Bila paramedis merasa aman, baik fisik maupun psikis, maka komitmen akan muncul dengan sendirinya. Misalnya, paramedis merasa aman karena rumah sakit membuat kebijakan memberikan kesempatan paramedis bekerja selama usia produktif. Membangun komitmen paramedis di rumah sakit merupakan proses yang panjang dan tidak bisa dibentuk secara instan. Oleh karena itu rumah sakit harus benar-benar memberikan perlakuan yang benar pada masa awal paramedis memasuki rumah sakit, dengan demikian paramedis akan mempunyai persepsi yang positif terhadap rumah sakit. Tidak ada satu pimpinan organisasi manapun yang tidak menginginkan seluruh jajaran anggotanya tidak memiliki komitmen yang kuat terhadap organisasi/perusahaan mereka. Bahkan sampai sejauh ini banyak pimpinan organisasi sedang berusaha menggiatkan peningkatan komitmen anggotanya terhadap organisasi, maka dengan menciptakan rasa kepemilikan terhadap rumah sakit, meyakinkan paramedis dalam manajemen serta menciptakan semangat dalam bekerja, rumah sakit dapat membentuk komitmen paramedis. Jika komitmen paramedis sudah terbentuk maka implementasi akreditasi rumah sakit bisa dilaksanakan dengan baik. 


\section{SIMPULAN}

Gaya kepemimpinan dan komitmen paramedis dalam implementasi akreditasi rumah sakit menunjukkan hubungan yang kuat dan berpola positif. Artinya semakin baik gaya kepemimpinan yang dipraktikan semakin baik komitmen paramedis yang terbentuk. Dalam penelitian ini ditemukan bahwa atasan langsung paramedis berusaha menerapkan berbagai gaya kempeimpinan dalam praktik kepemimpinannya untuk menguatkan komitmen paramedis dalam implementasi akreditasi dengan karakteristik paramedis berlatar belakang pindidikan D3 dan masa kerja kurang dari 5 tahun. Hasil penelitian menyimpulkan bahwa gaya kepemimpinan orientasi prestasi adalah gaya kepemimpinan yang dianggap paling mampu membangun komitmen paramedis dalam implementasi akreditasi.

\section{DAFTAR PUSTAKA}

Kemenkes RI. UU No 44 Tahun 2009 Tentang Rumah Sakit. Jakarta: Kemenkes RI.2009.

Kemenkes RI. PERMENKES RI NO. 12/MENKES/PER/IV/2012 Tentang Akreditasi Rumah Sakit. Jakarta: Kemenkes RI. 2012.

Kemenkes RI. PERMENKES RI NO. 56/MENKES/PER/VIII/2014 Tentang Klasifikasi dan Perijinan Rumah Sakit. Jakarta: Kemenkes RI.2014.

Aditama. C.Y. Manajemen Administrasi Rumah Sakit. Jakarta: UI Press.2013.

Restiawati EK.,Rudijanto K.,Wardhani V. Respon Pemimpin Rumah Sakit Terhadap Penerapan Akreditasi Rumah Sakit KARS Versi 2012. Jurnal Manajemen Pelayanan Kesehatan.Vol. 16, 1 Maret 2013,Hal 9-14.2013.

Mamduh, H., Manajemen, UPP AMP YKPN, Yogyakarta.2010.

Soekidjan. Manjaemen Sumber Daya Manusia. Jakarta: BumiAksara.2009.

Roscahyo. Pengaruh Gaya Kepemimpinan Terhadap Kinerja Karyawan Pada Rumah Sakit Siti Khodijah Sidoarjo. Jurnal Ilmu dan Riset Manajemen Vol 2 No 12 (2013).2013.

Yulistian A.S. Pengaruh Gaya Kepemimpinan Direktif, Suportif, Dan Orientasi Prestasi Terhadap Semangat Kerja Karyawan (Studi Pada Karyawan Bank Rakyat Indonesia Cabang Lamongan). Naskah publikasi. Malang: Universitas Brawijaya.2011.

Widiyanti. Pengaruh Gaya Kepemimpinan Prestasi Terhadap Kinerja Dengan Varibel Moderasi Partisipasi Pengambilan Keputusan dan Need for achiement. Jurnal ekonomi dan kewirausahaan Vol 12, No 2, Oktober 2012: 124-131.2012.

Thoha, Miftah., Kepemimpinan Dalam Manajemen, Jakarta: PT Raja Grafindo.2010. 